\section{Correspondence on "Efficacy of a tight-control and treat-to-target strategy in axial spondyloarthritis: results of the open-label, pragmatic, cluster-randomised TICOSPA trial" by Molto et al}

With great interest, we read the results of the tight control in spondyloarthritis (TICOSPA) study ${ }^{1}$ in which a tight-control/treat-to-target strategy (T2T) was compared with usual care in patients with axial spondyloarthritis (axSpA). In this study which was the first ever to use a T2T strategy in axSpA, a main outcome parameter was used that had never been used before: the percentage of patients with a $\geq 30 \%$ improvement on the 'Assessment of spondyloarthritis international society (ASAS)-Health Index (ASAS-HI), and other conventional efficacy outcomes were also recorded. ${ }^{1}$ As recently explained, one important reasons to use the ASAS HI in TICOSPA as primary endpoint was to avoid circular reasoning, for example, using the same items for inclusion and outcome. ${ }^{2}$

The aim of this correspondence is not to discuss the strategy used in the trial since this has been done in a recent editorial but to discuss the use of this outcome parameter which represents a tool that has been developed over many years with $>2000$ patients and a major input from patients. This is also documented by the fact that 5 items out of the 17 in the ASAS HI were proposed by patients with ankylosing spondylitis (AS) and they are not part of any other tool that has been used in axSpA. ${ }^{3}$

The ASAS HI is a disease-specific health index designed to assess global functioning and health in patients with axSpA that had originally been started to overcome the problem to define disease severity because this domain contains many different aspects of the disease: disease activity, damage, reduced mobility, reduced physical function, reduced social participation. The impact of function and activity on the disease has recently been intensively reviewed. ${ }^{4}$ Thus, it comes close to the meaning of impact of the disease. The impact of the disease might be related to quality of life, but is even a bit broader than the subjective experience of those problems. This broader concept is included in the International Classification of Functioning, Disability and Health (ICF) which has been published by the world health organisation (WHO) in 2001. The ICF represents an universally accepted model that classifies and describes functioning, disability and health in individuals with a wide spectrum of diseases or conditions in a systematic way. The term 'functioning' in the context of the ICF is equated more with 'health' than 'function' as the latter term is limited to physical function and ignores the complexity of global functioning. The ASAS HI covers areas of physical, emotional and social functioning based on categories summarised in the ASAS/WHO ICF core set for AS. ${ }^{5}$ Within the Comprehensive ICF Core Set, 80 categories were selected which describe the typical spectrum of problems related to the functioning of patients with AS in a multidisciplinary assessment, 66 items relate to functioning and 14 to environmental factors which have recently been looked at in more detail. ${ }^{6}$

The ASAS HI is a 17 -item instrument covering sum scores ranging from 0 (good health) to 17 (poor health). Each item consists of one question that the patient needs to respond to with either 'I agree' (score 1), 'I do not agree' (score 0 ). An improvement $\geq 3$ from baseline in ASAS HI represents a clinically meaningful change and attaining a 'good health status' is defined by score $\leq 5{ }^{7}$ The ASAS HI has been extensively evaluated. When patients were asked to rate items the highest relative importance was assigned to pain, sleep, being exhausted, standing and motivation to do anything that requires physical effort, while the lowest was assigned to sexual relationships, toileting, contact with people, driving and washing hair. ${ }^{8}$

There is limited information with regard to which items are best influenced by biologic disease modifying (bDMARD) therapy. There are two studies on treatment with $\mathrm{r}$-axSpA $\mathrm{A}^{9}$ and $\mathrm{nr}-\mathrm{axSpA} \mathrm{A}^{10}$ with ixekizumab. The vast majority ( $>95 \%$ ) of bDMARD-naïve patients had an ASAS HI $\geq 3$ at baseline. About $50 \%$ of $\mathrm{r}$-axSpA and nr-axSpA patients on ixekizumab achieved an improvement of the ASAS HI score $>3$ at weeks 16 and 52, respectively. The results at week 16 were similar for the comparator adalimumab but the placebo response rate was also quite high with $34.5 \%{ }^{10}$ Significantly more nr-axSpA patients on ixekizumab reported improvements in ASAS HI 'good health status' (ASAS $\mathrm{HI} \leq 5$ ) at weeks 16 and 52, respectively. ${ }^{10}$ In another study evaluating the clinimetric properties of the ASAS HI, a value of 4 was found to be indicate inactive disease. However, there is still a need to detect the most responsive items of the ASAS HI and to clarify whether these are consistent with patients' needs.

On this basis, what does it mean to reach a $30 \%$ reduction of ASAS HI ? In the recently published trials on ixekizumab the baseline value of the ASAS HI was between 8 and $10 .{ }^{90}$ In TICOSPA, the mean ASAS HI was 8.2 in the T2T and 9 in the control group which required statistical adjustments. Furthermore, since the ASAS HI outcome was used for the first time, the sample size calculation was not easy, and it can be calculated that, if 20 patients more in each arm would have been included the primary outcome would have been reached.

Nevertheless, the outcome $\geq 30 \%$ improvement of the ASAS HI is not yet validated, its choice was not data driven but there was reason to use it which is much appreciated. However, an evaluation should be performed and we hope that companies provide data for that. In that line, the standardised response mean of the ASAS HI requires a cut-off of $\geq 3$.0 ASAS HI scoring points, ${ }^{3}$ this should be taken into account.

In summary, we do think that the ASAS HI is a useful outcome instrument in clinical trials which, in addition to disease activity and function, is able to convince us about an improvement that made a real difference for patients.

\section{Uta Kiltz $\odot$, Juergen Braun $\odot$}

Rheumazentrum Ruhrgebiet, Ruhr Universität Bochum, Herne, Germany

Correspondence to Dr Juergen Braun, Rheumazentrum Ruhrgebiet, Herne 44649, Germany; juergen.braun@elisabethgruppe.de

Contributors Both authors have equally contributed.

Funding The authors have not declared a specific grant for this research from any funding agency in the public, commercial or not-for-profit sectors.

\section{Competing interests None declared.}

Patient and public involvement Patients and/or the public were not involved in the design, or conduct, or reporting, or dissemination plans of this research.

Patient consent for publication Not applicable.

Provenance and peer review Commissioned; internally peer reviewed.

(C) Author(s) (or their employer(s)) 2021. No commercial re-use. See rights and permissions. Published by BMJ.

UK and JB contributed equally.

$$
\text { Check for updates }
$$

To cite Kiltz U, Braun J. Ann Rheum Dis Epub ahead of print: [please include Day Month Year]. doi:10.1136/annrheumdis-2021-221423

\section{Received 6 September 2021}

Accepted 7 September 2021

Ann Rheum Dis 2021;0:1. doi:10.1136/annrheumdis-2021-221423

\section{ORCID iDs}

Uta Kiltz http://orcid.org/0000-0001-5668-4497

Juergen Braun http://orcid.org/0000-0002-9156-5095

\section{REFERENCES}

1 Molto A, López-Medina C, Van den Bosch FE. Efficacy of a tight-control and treat-totarget strategy in axial spondyloarthritis: results of the open-label, pragmatic, clusterrandomised TICOSPA trial. Ann Rheum Dis 2021.

2 Kiltz U, Wendling D, Braun J. ASAS Health Index: The "All in One" for Spondyloarthritis Evaluation? J Rheumatol 2020:47:1457-60.

3 Kiltz U, van der Heijde D, Boonen A, et al. Development of a health index in patients with ankylosing spondylitis (ASAS HI): final result of a global initiative based on the ICF guided by ASAS. Ann Rheum Dis 2015;74:830-5.

4 Braun J, Baraliakos X, Kiltz U. Nature Rev Rheum 2021 Nat Rev Rheumatol 2021 Sep;17(9):565-576. online ahead of print July 26th.

5 Boonen A, Braun J, van der Horst Bruinsma IE, et al. ASAS/WHO ICF core sets for ankylosing spondylitis (as): how to classify the impact of as on functioning and health. Ann Rheum Dis 2010;69:102-7.

6 Kiltz Uet al. Development of an environmental contextual factor item set relevant to global functioning and health in axial spondyloarthritis patients. Rheumatology 2021.

7 Kiltz U, van der Heijde D, Boonen A, et al. Measurement properties of the ASAS health index: results of a global study in patients with axial and peripheral spondyloarthritis. Ann Rheum Dis 2018;77:1311-7.

8 Kiltz U, Essers I, Hiligsmann M, et al. Which aspects of health are most important for patients with spondyloarthritis? A best worst scaling based on the ASAS health index. Rheumatology 2016;55:1771-6.

9 Kiltz U, Wei JC-C, van der Heijde D, et al. Ixekizumab improves functioning and health in the treatment of radiographic axial spondyloarthritis: week 52 results from 2 pivotal studies. I Rheumatol 2021;48:188-97.

10 Walsh JA, Magrey MN, Baraliakos X, et al. Ixekizumab improves functioning and health in the treatment of active Non-Radiographic axial spondyloarthritis: 52-Week results, COAST-X trial. Arthritis Care Res 2020. doi:10.1002/acr.24482. [Epub ahead of print: 12 Oct 2020]. 